\title{
Analysis of the effectiveness of thermal insulation of a multi-layer reinforced concrete slab using layer of concrete with low thermal conductivity under the climatic conditions of Vietnam
}

\author{
$V u$ Dinh Tho ${ }^{*}$, Elena Korol and Nguyen Huy Hoang \\ Moscow State University of Civil Engineering, Yaroslavskoe shosse, 26, Moscow, 129337, Russia
}

\begin{abstract}
Multi-layer reinforced concrete slabs with thermal insulation materials are widely used in practice all over the world. In Vietnam, in order to apply modern construction of multi-layer structures with an inner layer of low thermal conductivity concrete into practice, it is necessary to conduct numerical researches on the peculiarities of the country climatic conditions country. In this paper, the authors analyze the heat transfer in multilayer reinforced concrete slabs' roof under the climatic conditions of Hanoi (Vietnam) using finite element method with computer simulation. The object of the study is the insulating capacity of multilayer reinforced concrete roofs under the influence of changes in the temperature of the outer surface of the structure of the buildings' roof. The research methods are based on the numerical simulation of heat transfer from the outer to the inner surface of the building roof. From the results obtained, compared to the traditional design solution, multilayer reinforced concrete slab appears to have more advantages, and these advantages are available with the use of heat-insulating material made of polystyrene concrete. These scientific researches enable to choose the rational roof design in Vietnam, which satisfies the demand to reduce influence of temperature.
\end{abstract}

\section{Introduction}

Vietnam is located in the sub-Equatorial monsoon climate. Winter in the North of Vietnam is cold, the air temperature sometimes drops to $1^{\circ} \mathrm{C}$. In the Summer in the North of Vietnam, the highest temperature can reach up to $50^{\circ} \mathrm{C}$, taking into account the influence of solar radiation. Therefore, the structure of the building roof must provide the required heat transfer resistance for the operating conditions of the buildings with internal temperature between $(20-25)^{0} \mathrm{C}$ for the climatic conditions of Hanoi (Vietnam) to guarantee the coolness in summer and warmth in winter [1].

\footnotetext{
* Corresponding author: vuthoks@gmail.com
} 
In traditional technology, people apply conventional concrete slabs and work progress, in which waterproofing and water disposal - which increases the labor intensity.

Today, there are many new materials and new structures with high thermal insulation and at the same time simplify in the production of works. One of these solutions is a multilayer reinforced concrete slab using heat-insulating material made of polystyrene. Author's publications $[2,3,4,5,6 \ldots]$ showed that a reinforced concrete slab with a interior layer of concrete with low thermal conductivity has many advantages including reduction of heat conduction...Under the climatic conditions of Vietnam, it is necessary to assess the effectiveness of application of multilayer reinforced concrete slab about the ability of heat transfer. There are theoretical and empirical formulas for solving heat transfer problems in a multi-layer reinforced concrete slab.

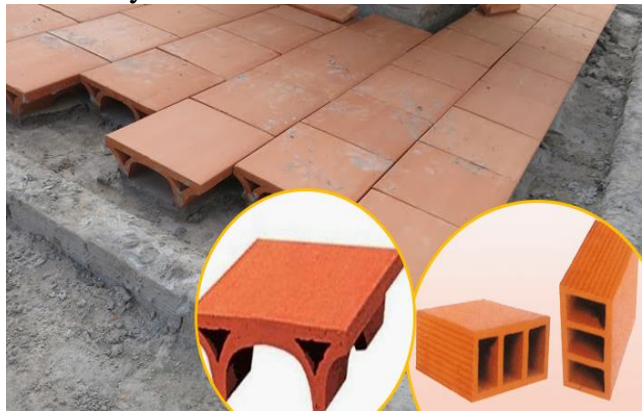

Fig. 1. Heat insulation for roof using hollow brick

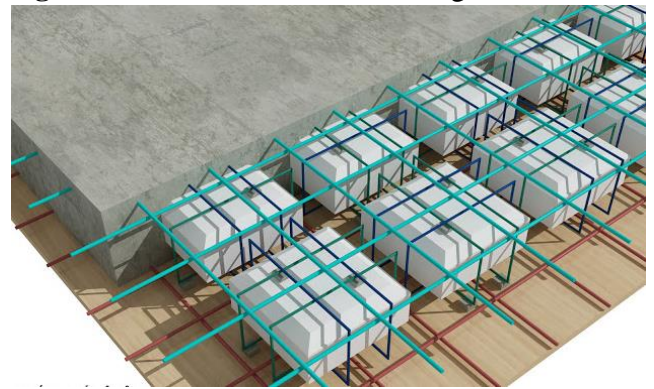

Fig. 3. Heat insulation for roof using foam block

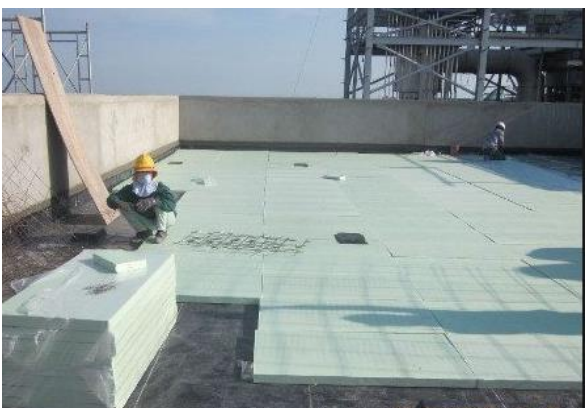

Fig. 12. Heat insulation for roof using foam

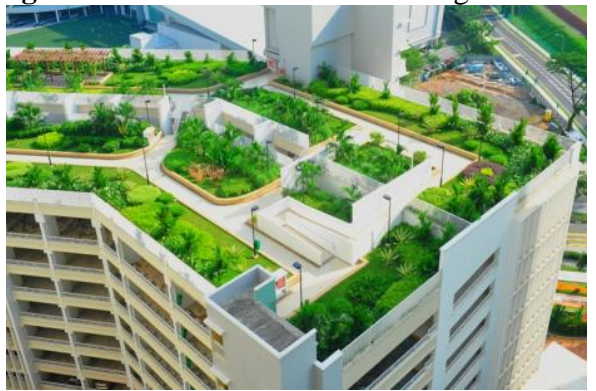

Fig. 4. Thermal insulation for roof using green cover

To provide the required insulation, the amount of heat transfer resistance of the building roof layers must be greater than the required heat transfer resistance. However, it is difficult to determine the effectiveness of thermal insulation solutions of roofs for structures with heat-conducting inclusions. In this article, the authors evaluate the effectiveness of some insulation solutions in climatic conditions of Vietnam and evaluate the effectiveness of thermal insulation solution by three-layer reinforced concrete structures with an inner layer of polystyrene using the finite element method (ANSYS) [8]. This is a modern method that enables to analyze and intuitively consider the thermal graph transfering process through the layers of the structure.

The analysis illustrates the potential of using multilayer reinforced concrete structure with an inner layer of low thermal conductivity concrete in Vietnam.

\section{Materials and methods of research}

The materials used in the analytical tasks of the study, are shown in table $1[9,10]$. 
Table 1. The characteristics of the materials used

\begin{tabular}{|c|l|c|}
\hline No. & The material within layers & \multicolumn{1}{|c|}{ Material characteristic of the layers } \\
\hline 1 & Ceramic tile & $\lambda=0,81 \mathrm{~W} /(\mathrm{m} . \mathrm{K}) ; \mathrm{C}=0,81 \mathrm{~kJ} / \mathrm{kg} .{ }^{0} \mathrm{~K} ; \gamma=1800 \mathrm{~kg} / \mathrm{m}^{3}$ \\
\hline 2 & Mortar layer & $\lambda=0,93 \mathrm{~W} /(\mathrm{m} . \mathrm{K}) ; \mathrm{C}=0,84 \mathrm{~kJ} / \mathrm{kg} .{ }^{0} \mathrm{~K} ; \gamma=1800 \mathrm{~kg} / \mathrm{m}^{3}$ \\
\hline 3 & $\begin{array}{l}\text { Porous bricks with rectangular } \\
\text { holes 120x200mm }\end{array}$ & $\lambda=0,81 \mathrm{~W} /(\mathrm{m} . \mathrm{K}) ; \mathrm{C}=0,88 \mathrm{~kJ} / \mathrm{kg} .{ }^{0} \mathrm{~K} ; \gamma=1800 \mathrm{~kg} / \mathrm{m}^{3}$ \\
\hline 4 & Slag concrete & $\lambda=0,41 \mathrm{~W} /(\mathrm{m} . \mathrm{K}) ; \mathrm{C}=0,75 \mathrm{~kJ} / \mathrm{kg} .{ }^{0} \mathrm{~K} ; \gamma=1000 \mathrm{~kg} / \mathrm{m}^{3}$ \\
\hline 5 & Waterproof cement & $\lambda=0,93 \mathrm{~W} /(\mathrm{m} . \mathrm{K}) ; \mathrm{C}=0,84 \mathrm{~kJ} / \mathrm{kg} .{ }^{0} \mathrm{~K} ; \gamma=1900 \mathrm{~kg} / \mathrm{m}^{3}$ \\
\hline 6 & Concrete Slab_B12,5 & $\lambda=1,55 \mathrm{~W} /(\mathrm{m} . \mathrm{K}) ; \mathrm{C}=0,84 \mathrm{~kJ} / \mathrm{kg} .{ }^{0} \mathrm{~K} ; \gamma=2400 \mathrm{~kg} / \mathrm{m}^{3}$ \\
\hline 7 & Polystyrene concrete B1,5 (D350) & $\lambda=0,095 \mathrm{~W} /(\mathrm{m} . \mathrm{K}) ; \mathrm{C}=0,88 \mathrm{~kJ} / \mathrm{kg} .{ }^{0} \mathrm{~K} ; \gamma=350 \mathrm{~kg} / \mathrm{m}^{3}$ \\
\hline 8 & Polystyrene & $\lambda=0,04 \mathrm{~W} /(\mathrm{m} \cdot \mathrm{K}) ; \mathrm{C}=1,38 \mathrm{~kJ} / \mathrm{kg} .{ }^{0} \mathrm{~K} ; \gamma=38 \mathrm{~kg} / \mathrm{m}^{3}$ \\
\hline
\end{tabular}

Under the climatic conditions of Hanoi, the required heat transfer resistance $\left(\mathrm{R}_{0 \mathrm{yc}}\right)$ is determined by the formula (17) and (23) standard TCVN 4605-1988 [9] "Heating techniques - insulating component - Designs standard" и QCVN 09-2013 [10] "National technical regulation on Energy efficiency building" $\mathrm{R}_{0 \mathrm{yc}} \geq 1,00\left(\mathrm{~m}^{2} . \mathrm{K} / \mathrm{W}\right)$ is obtained ; the calculated temperature of the interior air $\mathrm{t}_{\mathrm{t}}=20^{\circ} \mathrm{C}$; Calculated temperature of the outside air $\mathrm{t}_{\mathrm{n}}=5^{\circ} \mathrm{C}$ in winter $\& \mathrm{t}_{\mathrm{n}}=30,3^{\circ} \mathrm{C}$ in the summer, when considering solar radiation factors and other conditions, the estimated outdoor temperature is determined by: $\mathrm{t}_{\mathrm{tg}} \cdot \mathrm{t}_{\mathrm{b}}=\mathrm{t}_{\mathrm{n}}+\varphi \cdot \mathrm{I}_{\mathrm{tb}} / \alpha_{\mathrm{n}}=49.64^{0} \mathrm{C} \approx 50^{\circ} \mathrm{C}$; the heat transfer coefficient of the inner surface of the enclosing structure, for smooth ceilings is $\alpha_{\mathrm{t}}=5,9 \mathrm{~W} / \mathrm{m}^{2} . \mathrm{K}$ - (table 3 - TCVN 4605-1988); heat transfer coefficient (for winter conditions) of the outer surface of the enclosing structure, for roofs equal to Hanoi, $\alpha_{n}=25\left(\mathrm{~W} / \mathrm{m}^{2} . \mathrm{K}\right)$ - (table $4 *$ TCVN 4605-1988).

In this article, the authors use three-layer slabs, which have an external layer of concrete class B12, 5, the thickness of the external layers of $40 \mathrm{~mm}$ and the inner layer of concrete with low thermal conductivity, with a compression resistance of the order of 1.5 MPa (D350) $[2,3,11,12]$. The thickness of the inner layer $\mathrm{x}(\mathrm{mm})$ is determined from the required heat transfer resistance in Vietnam.

Heat transfer resistance $R_{0},\left(\mathrm{~m}^{2} . \mathrm{K} / \mathrm{W}\right)$, we find the formula (1) TCVN 4605-1988 [9] " Heating techniques-insulating component-Designs standard"

$$
R_{0}=\frac{1}{\alpha_{t}}+R_{k c}+\frac{1}{\alpha_{n}}
$$

$\mathrm{R}_{\mathrm{kc}}$ - thermal resistance of the enclosing structure with successive homogeneous layers, defined as the sum of the thermal resistances of the individual layers.

Under the climatic conditions of Hanoi, by substituting in the original formula (1), numerical values are found.

$$
R_{0}=\frac{1}{5,9}+\frac{0,04}{1,55}+\frac{x}{0,095}+\frac{0,04}{1,55}+\frac{1}{25} \geq R_{\text {oyc }}=1\left(m^{2} . K / \mathrm{W}\right) \Rightarrow \mathrm{x} \geq 0,07 \mathrm{~m}
$$

The thickness of the inner layer $\mathrm{x}=0,12 \mathrm{~m}$. Three-layer plate heat transfer resistance $\mathrm{R}_{0}=1,54\left(\mathrm{~m}^{2} .{ }^{0} \mathrm{~K} / \mathrm{W}\right)$, and plate thickness $\mathrm{h}=0,04+0,12+0,04=0,2(\mathrm{~m})$.

The size of the sandwich plate $1500 \times 6000 \times 200 \mathrm{~mm}$ (figure 5).

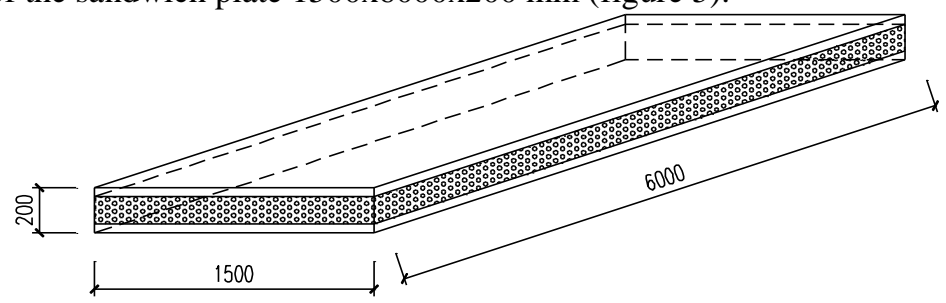

Fig. 5. The size of the sandwich plate $1500 \times 6000 \times 200 \mathrm{~mm}$ 
To assess the possibility of using three-layer panels to improve the required heat transfer for the roof, the authors will solve following problems:

- Comparison of the possibility of insulation of three-layer plates (TN-1-in table.2) with thermal insulation of several thermal insulation roof designs, which are commonly used in Vietnam (TN-2, TN-3 and TN-4 in table.2).

- Comparison of the possibility of insulation of three-layer plates (TN-1-in table.2) with thermal insulation of two solutions of thermal insulation roof designs offered in Vietnam standard (TN-5 and TN-6 in table.3).

Table 2. Some thermal insulation for roof design solutions, plate thickness $200 \mathrm{~mm}$

\begin{tabular}{|c|c|c|}
\hline No. & Section of the roof slabs & Details of the layers \\
\hline $\mathrm{TN}-1$ & 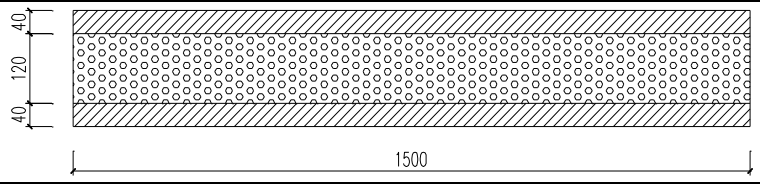 & $\begin{array}{l}\text { External layer: concrete } \\
\text { B12,5, thickness 50mm. } \\
\text { - Interior layer: Polystyrene } \\
\text { concrete B1,5 (D350), } \\
\text { thickness } 120 \mathrm{~mm} .\end{array}$ \\
\hline $\mathrm{TN}-2$ & & $\begin{array}{l}\text { - Reinforced concrete structure } \\
\text { B12,5, thickness } 200 \mathrm{~mm} \text {. }\end{array}$ \\
\hline $\mathrm{TN}-3$ & 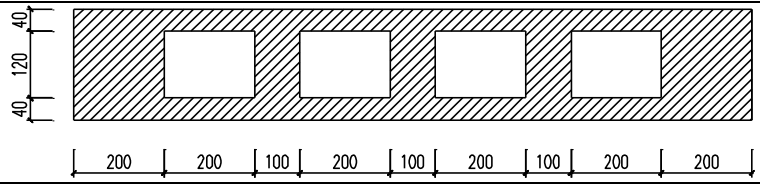 & $\begin{array}{l}\text { - Reinforced concrete structure } \\
\text { (B12,5), thickness } 200 \mathrm{~mm} \\
\text { with hole } 120 \times 200 \mathrm{~mm} \text {. }\end{array}$ \\
\hline $\mathrm{TN}-4$ & 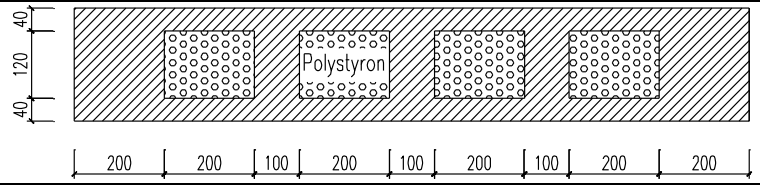 & $\begin{array}{l}\text { - Reinforced concrete structure } \\
\text { (B12,5), thickness } 200 \mathrm{~mm} \text {, } \\
\text { with foam block } 120 \times 200 \mathrm{~mm}\end{array}$ \\
\hline
\end{tabular}

Table 3. Two solutions of thermal insulation roof structures offered in standard Vietnam (QCVN 092013) [10]

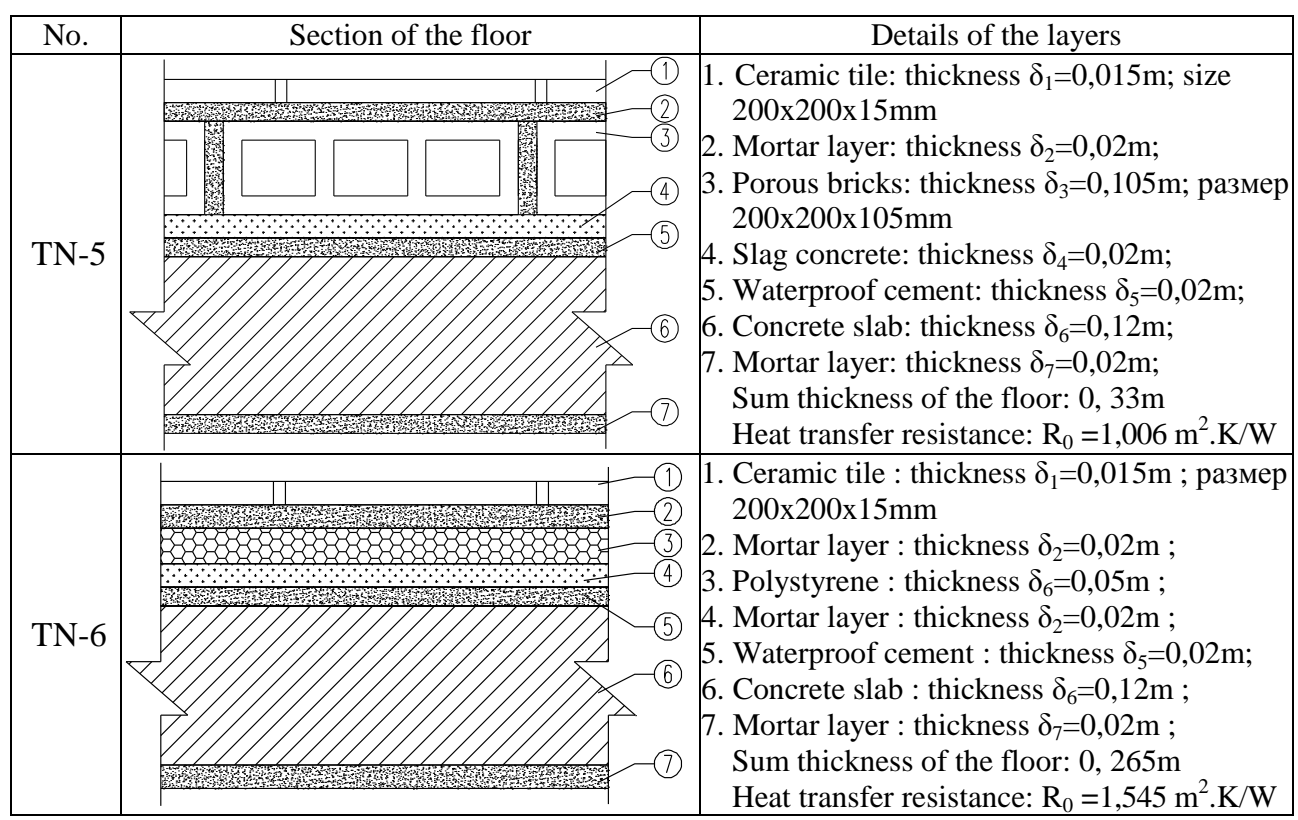


The authors analyze the heat transfer in a multi-layer reinforced concrete slab with the help of a complex computer program ANSYS, which is one of the modern programs, allowing users to put in necessary data, for example: thickness, physical and mechanical characteristics, etc. So that the results are approximate to the empirical results.

The heat transfer equation in multilayer reinforced concrete slab [8]:

$$
\frac{\partial}{\partial x}\left(\lambda_{x} \frac{\partial t}{\partial x}\right)+\frac{\partial}{\partial y}\left(\lambda_{y} \frac{\partial t}{\partial y}\right)+\frac{\partial}{\partial z}\left(\lambda_{z} \frac{\partial t}{\partial z}\right)=\rho c \frac{\partial t}{\partial \tau}
$$

With: $\mathrm{t}(\mathrm{x}, \mathrm{y}, \mathrm{z}, \mathrm{t})-$ temperature in coordinates $(\mathrm{x}, \mathrm{y}, \mathrm{z})$ at time $\mathrm{t}\left({ }^{0} \mathrm{C}\right)$;

$\lambda_{\mathrm{x}}, \lambda_{\mathrm{y}}, \lambda_{\mathrm{z}}-$ thermal conductivity coefficients of concrete along the $\mathrm{x}, \mathrm{y}, \mathrm{z}$ axes $\mathrm{W} /\left(\mathrm{m} .{ }^{0} \mathrm{~K}\right)$;

c - specific heat $\left(\mathrm{kJ} / \mathrm{kg} .{ }^{0} \mathrm{~K}\right)$;

$\rho$ - density $\left(\mathrm{kJ} / \mathrm{kg} .{ }^{0} \mathrm{~K}\right)$.

\section{Results and discussion}

\subsection{Comparison of the possibility of insulation of three-layer plates (TN-1 in table.2) with thermal insulation of several thermal insulation roof designs, which are commonly used in Vietnam (TN-2, TN-3 and TN-4 in table.2)}

Using software ANSYS 18.0, the authors analyze heat transfer through roof structures (TN$1, \mathrm{TN}-2, \mathrm{TN}-3$ and $\mathrm{TN}-4$ in table 2) with material parameters in table 1 and climatic conditions in Hanoi, Vietnam. In summer, the calculated air temperature of the outer surface of the enclosing structure $t_{n}=50^{\circ} \mathrm{C}$ and the air temperature of the inner surface of the enclosing structure $t_{t}=20^{\circ} \mathrm{C}$. The results are shown in figures $6,7,8,9$ and 10 .
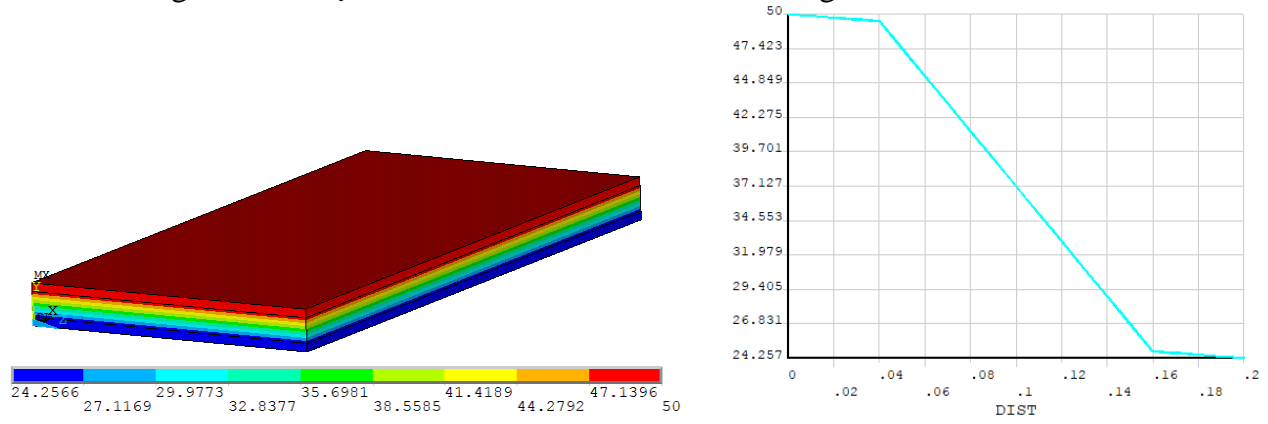

Fig. 6. Temperature distribution over the thickness of a multilayer reinforced concrete slab (TN-1)
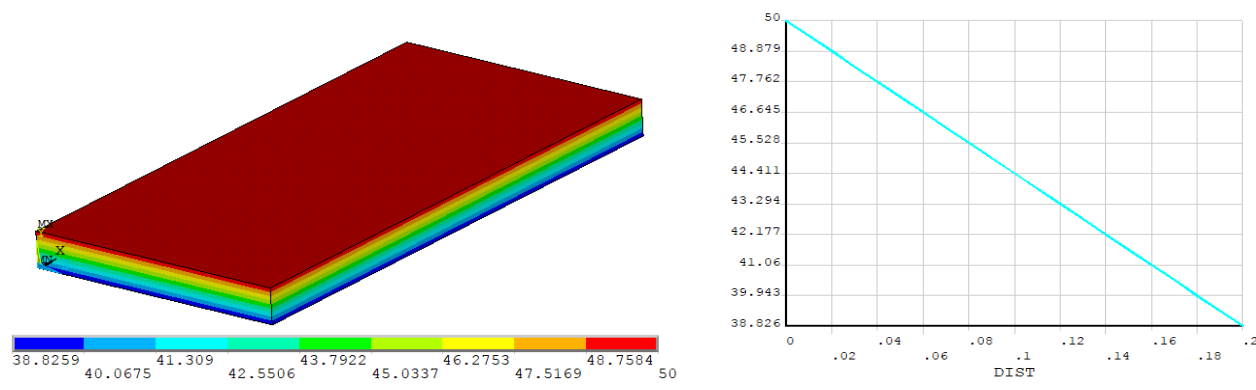

Fig. 7. Temperature distribution over the thickness of reinforced concrete slab (TN-2) 

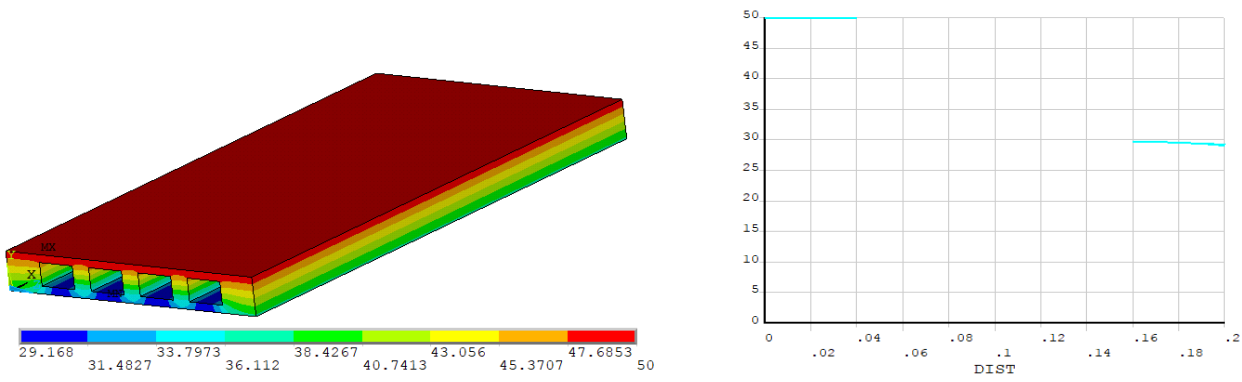

Fig. 8. Temperature distribution over the thickness of the hollow reinforced concrete slab (TN-3)
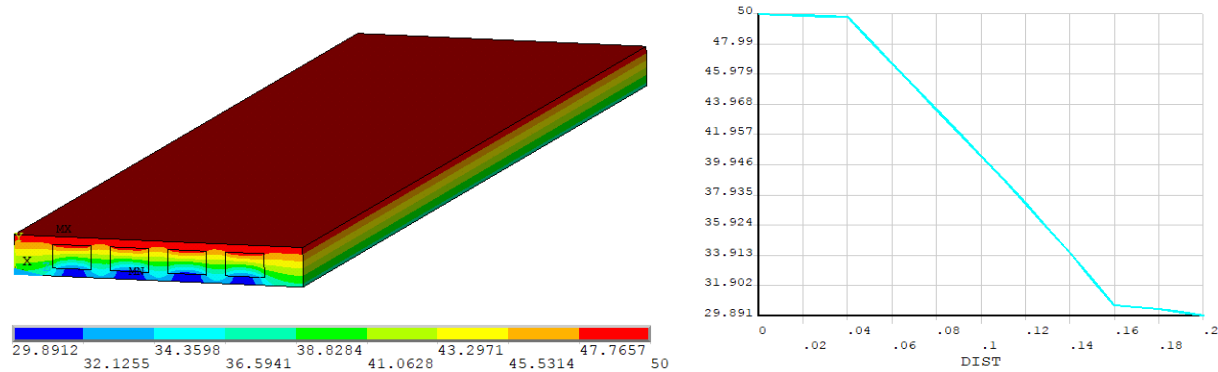

Fig. 9. Temperature distribution in reinforced concrete slab (using polystyrene block) TN-4

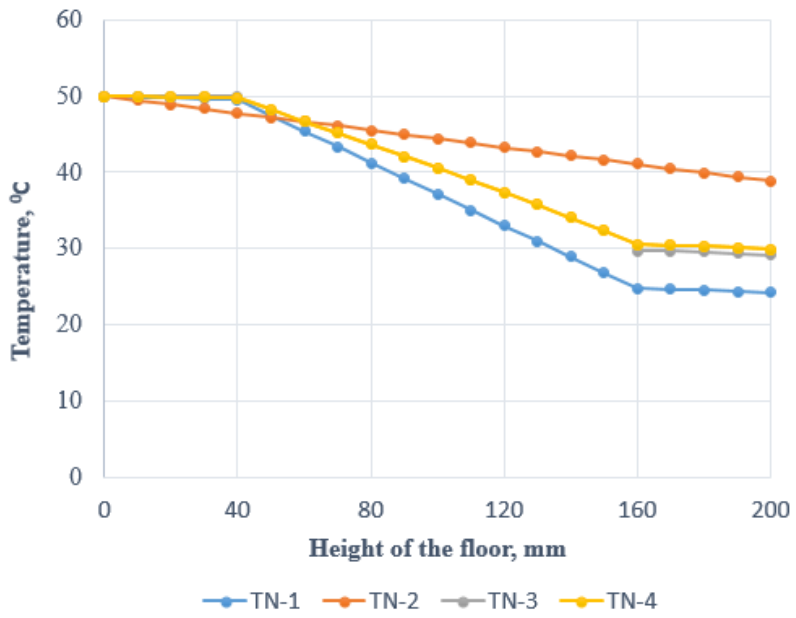

Fig.10. Comparison chart of heat distribution over thickness of slabs (TN-1, TN-2, TN-3 и TN-4)

The results of the analysis illustrate that at the same thickness of $200 \mathrm{~mm}$, a three-layer plate with an interior layer of low thermal conductivity concrete has more possibility of thermal insulation (compared to other types of structures) than other types of structures mentioned. The temperature of the inner surface of three-layer structure of the roof will increase $4,26^{\circ} \mathrm{C}$; solid concrete slab will increase $18,83^{\circ} \mathrm{C}$; hollow concrete slab (porosity $32 \%$ ) will increase $9,168^{\circ} \mathrm{C}$ and reinforced concrete slab (polystyrene blocks inserted, $32 \%$ of the area of the plane) will increase $9,891^{\circ} \mathrm{C}$. 


\subsection{Comparison of the possibility of insulation of three-layer plates (TN-1-in table.2) with thermal insulation of two solutions of thermal insulation roof designs (TN-5 and TN-6 in table.3) offered in standard of Vietnam [10]}

As in sections (a), the authors consider that the temperatures of the internal and external surfaces of the roof structure are $\mathrm{t}_{\mathrm{n}}=50^{\circ} \mathrm{C}$ and $\mathrm{t}_{\mathrm{t}}=20^{\circ} \mathrm{C}$ for the analysis of heat transfer processes through the roof structures (in table 3 ) on ANSYS programs. The results are shown in figures 11 and 12.
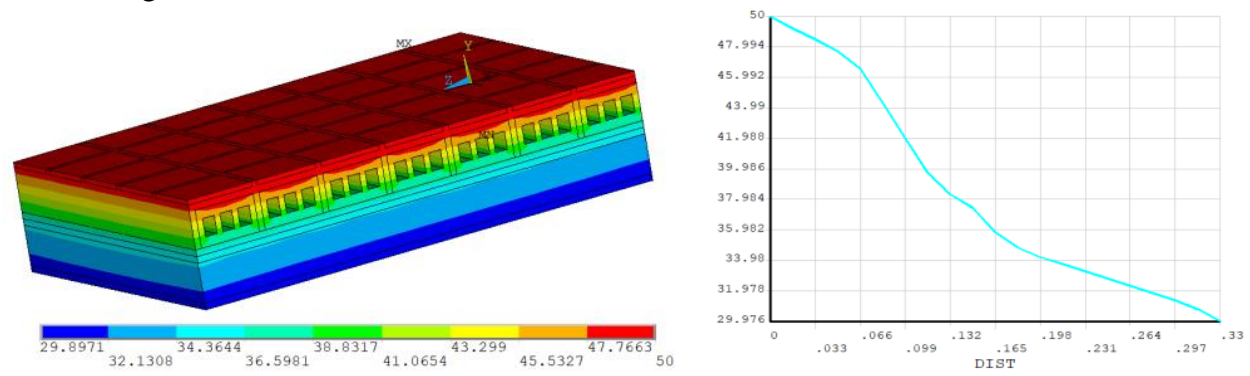

Fig.11. The temperature distribution over the thickness of the plate TN-5
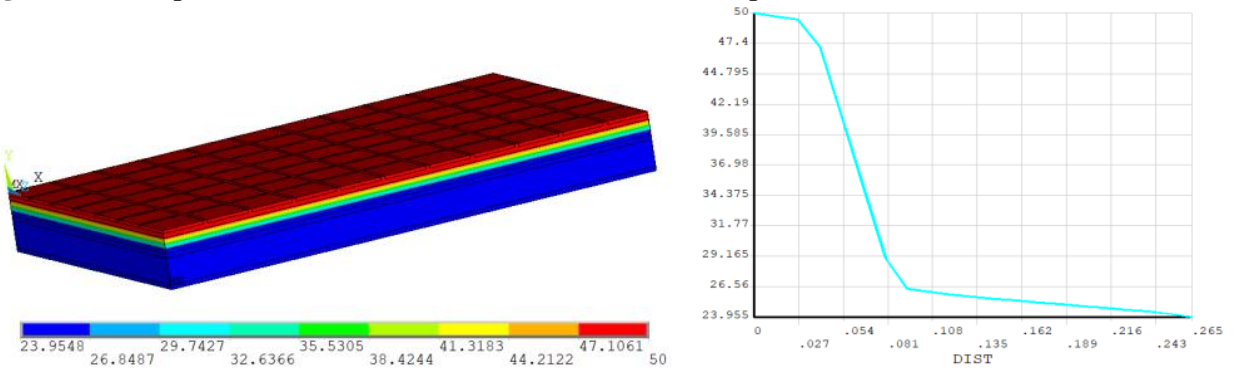

Fig.12. The temperature distribution over the thickness of the plate TN-6

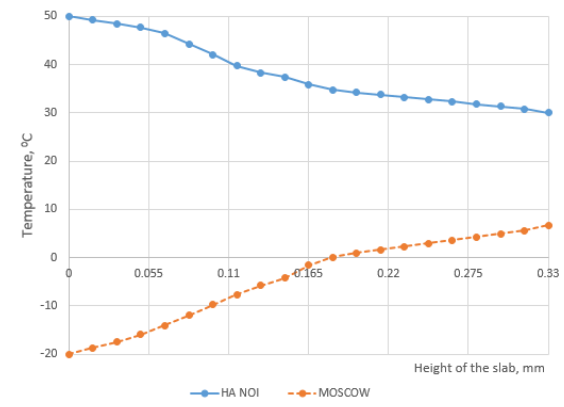

a)

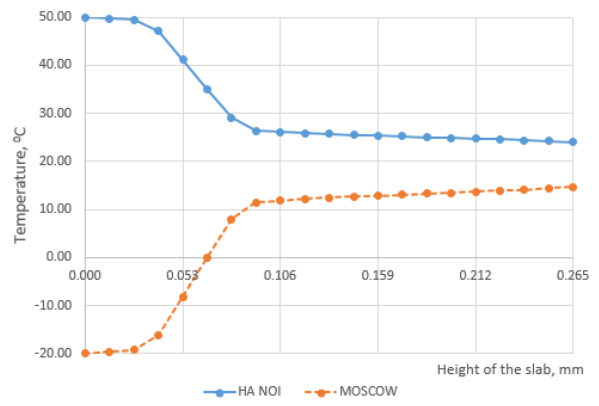

b)

Fig.13. The temperature distribution over the thickness of the roof structure TN-5 (a) \& TN-6 (b)

Similarly, analyze of heat transfer through the roof structure TN-5 and TN-6, when the external temperature of roof structure is $t_{n}=-20^{\circ} \mathrm{C}$, the internal temperature is $t_{t}=20^{\circ} \mathrm{C}$ (corresponding to temperature in Moscow). The results of analysis of heat transfer through the structure with the conditions weather in Hanoi and Moscow are then compared. The results are shown in figures $13 \mathrm{a}$ and $13 \mathrm{~b}$.

The results of the analysis of heat transfer on some types of structures demonstrate that the three-layer reinforced concrete structure has a smaller thickness than other structural solutions with a thermal insulation layer of polystyrene.

In Vietnam, the biggest problem is eliminating the thermal insulation from outside into the buildings, which is opposite in countries with cold winter period (exp: Russia). 
Therefore, this study considering the potential and appropriate aspects of the three-layer reinforced concrete structure under the climatic conditions of Vietnam has great pratical meaning.

\section{Conclusions}

1. Three-layer reinforced concrete roof with an inner layer of concrete with low thermal conductivity is a rational, technological constructing solution under the climatic conditions of Vietnam, which allows to provide the required parameters of the microclimate, creating a comfortable mode for indoor-life.

2. The advantages of the investigated three-layer design compared to traditional solutions are: increasing thermal uniformity due to the reduction of heat-conducting inclusions and increasing manufacturability by reducing the duration and complexity of work.

3. The use of lightweight concretes with low thermal conductivity as a thermal insulation layer of three-layer reinforced concrete roof structures can increase the structural strength of the insulation, along with the overall durability and reliability of the structure.

This work was financially supported by Ministry of Science and Higher Education of the Russian Federation (\#NSh-3492.2018.8).

\section{References}

1. QCVN 02-2009, "Vietnam building code natural Physical \& Climatic data for construction", (Standard, VietNam, 2009)

2. E.A. Korol, Three-layer enclosing reinforced concrete structures made of lightweight concrete and features of their calculation (Asv, Moc, 2001)

3. E.A. Korol, V. D. Tho, N. H. Hoang, MATEC Web Conf, 196, 02022 (2018)

4. E Korol, VD Tho, Y Kustikova, IOP Conference Series, 365 (5), 052033 (2018)

5. I. Bujnak, E.A. Korol, V.E. Latushkin, Communication, 1, 101 ( 2012)

6. E.A. Korol, Y.A. Kharkin, Vestnik MSSU, 3, 156-163 (2010)

7. Е.А. Король, Е.M. Pugach, A. Kharkinu, Vestnik MSSU, 3, 67 (2014)

8. S. Moaveni, Finite element analysis: Theory and application with ANSYS, (London, 2015)

9. TCVN 4605-1988, "Heating techniques - insulating component - Designs standard" (Standard, VietNam, 1988)

10. QCVN 09-2013, "National technical regulation on Energy efficiency building", (Standard, VietNam, 2013)

11.SP 63-13330-2012, Concrete and reinforced concrete structures (Standard, Rus, 2012)

12. GOST R 51263-2012, Polystyrene concrete. Technical conditions (Standard, Rus, 2012) 